\title{
University Teachers' Ambivalence about the Digital Transformation of Higher Education
}

\author{
Jeanette Sjöberg 1 \\ Halmstad University \\ Halmstad, Sweden \\ https://orcid.org/0000-0002-1147-5736 \\ Patrik Lilja \\ Halmstad University \\ Halmstad, Sweden \\ https:/ / orcid.org/0000-0001-7252-4610
}

\begin{abstract}
In contemporary higher education institutions, the digital transformation is obvious and necessary; new times call for new teaching approaches with the help from digital technology. This is a requirement not only from students but also from society at large, and it implies a partly changed teacher role, including digital competence alongside content, didactic and pedagogical competence. For many teachers this means an increased workload and stress, at the same time as they recognize the opportunities and possible benefits that digital tools offer. To provide a contribution to the understanding of the complexity that digital transformation in higher education means, we investigate how theoretical assumptions about technology integration in education relate to the teaching practice of university teachers. The article draws from two separate studies with university teachers, carried out in a small Swedish university; a survey with 254 respondents and a focus group interview with six participants. Results indicate that the teachers are hesitant yet positive towards using digital technology in their pedagogical practice and that there is ambivalence surrounding the issue at hand, as the integration of technology in teaching is connected to organizational and societal processes beyond their direct control. We argue that one-sided theoretical assumptions about technology integration may be an explanation of the situation where the practice and rhetoric of technology use in higher education diverge.
\end{abstract}

Keywords: Digital transformation; Digital technology; Higher education; TPACK framework; University teachers

${ }^{1}$ Corresponding author: Jeanette Sjöberg, Jeanette.sjoberg@hh.se 


\section{Introduction}

Teachers in higher educational institutions are nowadays expected to increasingly use various digital technologies in their teaching as well as to adopt active learning methods like project- and problem-based learning. This has led to changed expectations on the teacher role. Teachers are expected to be capable of acting as guides and/or facilitators with extensive digital competence (Selwyn, 2014). The digital competence of teachers is thought to strengthen the students' ability to use and understand digital systems and services as well as their ability to relate to media and information in critical and responsible ways. Furthermore, digital competence includes the ability to use the Internet and digital technology to support one's own professional practice. Hence, teachers within higher education will continuously be expected to develop their digital skills in order to use digital tools and services in accordance to their own needs as well as what is expected of them professionally (Redecker, 2017). The rhetoric often departs from the assumption that such ideals are already a reality (years ago). From the teachers' point of view, however, the picture is considerably more complex. On the one hand, the use of technologies such as email, learning management systems and various administrative systems have fundamentally changed the face of university teaching over the last decades. On the other, the apparent pedagogical use of these technologies is often limited to PowerPoint presentations and basic learning management system functionality (Selwyn, 2014). Given this situation and our positions as educational developers, we have taken interest in studying both the images and realities of digital competence among university teachers.

Educational development with the goal of integrating technology in education is often approached through theoretical frameworks and models that address and highlight teachers' individual level of competence and knowledge. One such framework, that has been rather influential the last 15 years, is the TPACK framework (Mishra \& Koehler, 2006). The key to technology integration in teaching is, from this point of view, to raise the level of knowledge in teachers, rather than developing organizational, institutional or cultural aspects. The emphasis of the central role of individual knowledge also seems to be consistent with both how teachers and management in higher education tend to view the use of digital technology in educational practice (Roumbanis Viberg, Forslund Frykedal, \& Sofkova Hashemi, 2019).

This complex and contradictory picture of the uses of digital technologies in higher education warrants further study, however, which has been recognized by several authors. For example, Castañeda and Selwyn (2018) are raising questions regarding how educational uses of digital technologies are shaped, conditioned and modified in actual settings that involve different types of influences. More specifically, Roumbanis Viberg, Forslund Frykedal, and Sofkova Hashemi (2019) are requesting research regarding what role the working conditions of teachers in higher education play in relation to the use of digital technology in teaching. On that note, the overall aim of this article is to investigate how theoretical assumptions about technology integration in 
education relate to the teaching practice of university teachers. Research questions posed are:

1) What experiences do higher education teachers have of teaching with digital technologies to support student learning?

2) What factors facilitate or limit teachers' use of digital technology in teaching within higher education?

3) What is the relationship between theoretical assumptions about practice in the TPACK framework and the teaching experience of university teachers?

\subsection{Digital Technology in Higher Education}

Previous research shows that the introduction of digital technology in higher education is a matter of priority but at the same time constantly complicated (Price \& Kirkwood, 2014; Singh \& Hardaker, 2014). This is often closely linked to the fact that there are different intentions and agendas that meet in the matter, where the universities as a structure often stand in opposition to the university teacher as an individual (Singh \& Hardaker, 2014). If this is the no conducive environment for the development of digital technology in teaching arises, either for the teacher or the educational institution, and thus also neither for the student (Price \& Kirkwood, 2014). In fact, the problems with implementing digital technology in higher education have been the object of discussion for quite some time now. Not seldom the difficulties of introducing digital technology into higher education have been explained, somewhat simplified, on the basis of assumptions of teachers' limited skills, and unwillingness to adopt digital tools in teaching (Taylor, 2014). However, this has been proven not entirely accurate; on the contrary, university teachers are in general much inclined in improving their teaching with the help of digital technology (Kirkwood \& Price, 2014; Price \& Kirkwood, 2014; Singh \& Hardaker, 2014; Roumbanis Viberg, et al., 2019). Often it is the students' need for a changed education that affects the teacher's interest in changing their teaching, which in turn leads to the search for evidence-based technology for improving teaching (Price \& Kirkwood, 2014). However, with the absence of - alternatively an unclear - strategy regarding digital technology from the university management, the teachers' work related to the integration of technology in teaching is made more difficult (Singh \& Hardaker, 2014). Aspects such as teachers' concerns over workload and the impact upon the learning experience, as well as anxieties over the teacher role are all parts of the explanation (Taylor, 2014). Meanwhile, from an organizational point of view, the assumption is made that if the university only provides the technology, the teachers will use it.

\subsection{Theoretical models of technology integration in teaching}

One of the most widespread theoretical frameworks used to study technology integration in education is the TPACK framework, originally introduced as the TPCK in Mishra and Koehler (2006). The acronym stands for Technological Pedagogical Content Knowledge and is an extension of the PCK (Pedagogical Content Knowledge) framework originating in the work of Shulman (1986), 
adding technological knowledge as a separate domain. According to Herring, Koehler and Mishra (2016), digital skills in the TPACK framework include: knowledge to search for information, communicate, interact and produce digitally; skills in using digital tools and services; an understanding of the transformation that digitalization entails in society with its opportunities and risks; motivation to participate in development; the ability to monitor digital development; as high an understanding of technology as for subject knowledge and pedagogy; being able to choose technology that is relevant to teaching; not selecting technology when it does not add value to the teaching context (Herring, Koehler, \& Mishra, 2016).

The TPACK-model (see Figure 1) is based on three areas of competence: subject/content, pedagogy and technology. The areas overlap and create new areas that in turn require new skills from the teacher. The core of the model, TPACK, is the optimal level of competence that shows how these three components interact together to provide support for good teaching. Outside the core, there is a dashed area that shows that the model should always be compared to the current context. When the teacher is confident in the use of technology, he or she must determine when the technology facilitates or becomes an obstacle in the learning process. The teacher should always relate to technology as a tool that is integrated and used if and when it adds value in the teaching context (Herring, Koehler, \& Mishra, 2016).

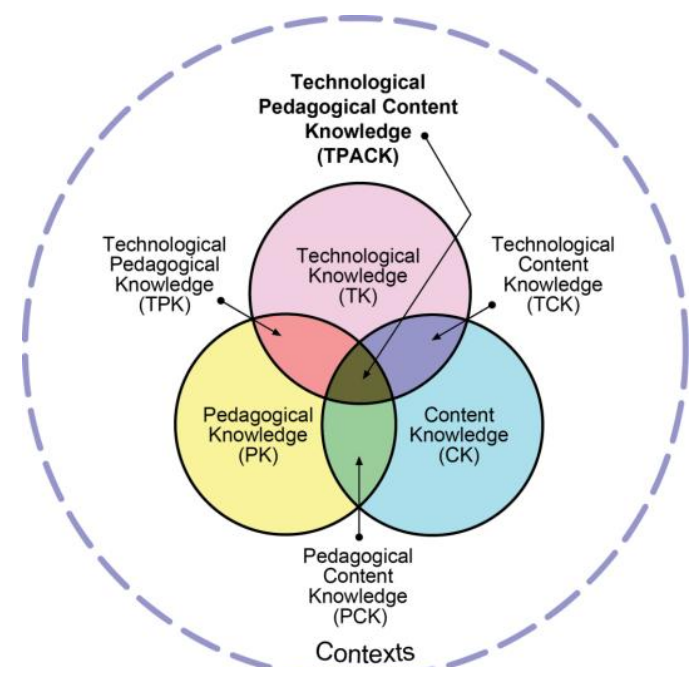

Figure 1: Technological Pedagogical Content Knowledge Framework (Mishra 2011; http://www.tpack.org)

In the TPACK framework, there is a clear focus on the knowledge and reasoning of the teacher and the local practice of planning, performing and evaluating teaching and learning. Ideally, digital technologies are appropriately used in learning processes and that can be rationally evaluated and improved (Mishra \& Koehler, 2006). A fundamental question motivating the analysis in this study is whether the theoretical premise of the TPACK framework, that technology integration can be fruitfully understood as a matter of teacher's knowledge and development of his or her local practice, is valid in the current situation for 
university teachers, a group that has been largely neglected in the TPACK literature (Herring, Mecham, \& Mourlam, 2016).

The literature on TPACK is extensive and consists to a great degree of attempts to develop instruments and measure TPACK by surveys. A dominating way of applying the framework is to use it in order to assess or measure teachers' individual level of knowledge of teaching with technology (Willermark, 2018). This is also the approach used in the first of the studies presented here. Besides the TPACK model, the survey used in this study was also informed by another approach developed to study teachers' ICT use in relation to technical competence development. Mandinach and Cline $(1992 ; 1994)$ have developed a model in which they describe four steps in teachers' technology use: survival stage, mastery stage, impact stage and innovation stage. In the first stage (survival), teachers typically struggle with technology, uses technology for directed instructions merely, have problems managing technology and have unrealistic expectations of what can be achieved academically by technology. In the second stage (mastery), teachers typically begin to be able to handle the technology better, to try new forms of interaction with students, to have increased acceptance of problems that arise with technology and to solve certain simpler technical problems on their own. In the third stage (impact), teachers typically have grown accustomed with technology use and are rarely threatened by it; they willingly share their experiences with colleagues, create technologyenhanced instructional units on a regular basis as well as regularly integrate new working relations and classroom routines. In the fourth and final stage (innovation), teachers typically have achieved an ability to handle technological problems on their own including updating and modifying their classroom and their teaching through technology-enhanced tools, in order to develop optimal learning situations. These four steps in teachers' technology use, or competence steps, coincides very well with the TPACK model, as is shown in Figure 2.

A further theoretical issue of relevance for the analyses presented here is the question of context in relation to the TPACK framework. Koh, Chai \& Tay (2014) suggests developing the framework to include physical/technological, cultural/institutional, interpersonal, and intrapersonal contexts. Other related suggestions include the approach of Pareto \& Willermark (2019), who suggests a more explicit focus on design processes rather than measurements. In this study, Koh, Chai \& Tay's (2014) interest in cultural and institutional contexts is developed in order to put the role of TPACK in higher education in perspective.

A theoretical framework that even further widens the view of context is the ecosocial approach of Lemke (2000). Lemke urges the researcher to question "what's going on, what's participating and how, and how one going-on is interdependent with another", rather than departing from a fixed framework (Lemke, 2000, p. 275). When exploring identity development, for example, Lemke suggests asking questions like: "what is the system, or network, within which a notion of 'identity' can be defined?" (p. 283). Answering such questions involves investigating the connection between processes taking place on different time scales. The ecosocial approach will be used as a theoretical 
contrast to the TPACK framework in the analysis of the second study presented here. It will be argued that approaching technology integration as a phenomenon connecting processes on different time scales can highlight crucial processes that are not addressed by the TPACK framework, thereby contributing to understanding the ambivalent character of university teachers' involvement with technology for educational purposes.

\section{Materials and methods}

The present article reports from two separate studies involving university teachers at a smaller Swedish university: a survey focusing digital competence with 254 responding university teachers (study 1), and a focus group interview with six university teachers on the subject of teaching with the support of digital technologies (study 2). The survey was based on the TPACK framework (Herring, Koehler, \& Mishra, 2016) and aimed to explore how competent and/or confident the teachers are when it comes to using digital technology in their teaching. The focus group discussion was conducted to explore university teachers' conceptions and reasoning about the use of digital technologies for educational purposes.

\subsection{Study 1: the survey}

As part of ongoing university pedagogical development work, a survey was carried out with the aim of identifying the teachers' level of competence and utilization of digital technology in their teaching. A further aim was to identify development areas for future supportive competence development efforts regarding digitization and digital competence. The concept of digital competence includes the knowledge, skills, understanding and motivation that the individual needs in the process of change that digitalization entails. The survey was developed out of the basis of the TPACK descriptions of what competencies a teacher needs to be able to work in a digitized world based on subject, pedagogy and didactics (Mishra \& Koehler, 2006).

The questions in the survey were developed with the aim of measuring the integration and application of technology in teaching contexts based on the TPACK model, which has been used with good results in several other studies in the same field (e.g. Akkaya, 2016; Bilici, Guzey, \& Yamak, 2016; Sancar-Tokmak \& Yanpar-Yelken, 2015). The survey also included questions aimed at getting a picture of the scope of use of the university's learning management system, as well as questions that indicate the teachers' wishes and/or need for support. In addition, the survey contained a couple of background questions, including the current teaching time for the past two years. In total, the survey contained 13 questions, of which 10 were matrix questions. A four-point Likert scale (ranging from "Totally agree", "Partially agree", "Agree with doubt" to "Disagree") was used to measure respondents' attitudes, and the scale "often, rarely, never" to measure the frequency of use of ICT tools. Even though the survey was based on self-assessing statements, we believe that the answers provide an indication of how extensive the teachers' experience and competence in the use of digital technology in teaching is. The questionnaire was distributed digitally to the teachers. A total of 263 respondents completed the survey, out of which 254 
were university teachers, which means a response rate of just above $53 \%$. The majority of respondents had on average more than $40 \%$ teaching time in their service over the past two years.

\subsubsection{Analysis of the survey}

The skills set out in the TPACK-model are focusing on three levels: technical knowledge, skillful application of technology and the ability to develop appropriate and context-specific strategies (for teaching). In the analysis of the survey results, the questions in the survey were related to these skills, which in turn were placed in a competence ladder based on the work by Mandinach and Cline (1992; 1994), who has defined four levels of competences which each contains skills that can be related to the TPACK-model (see Figure 2).

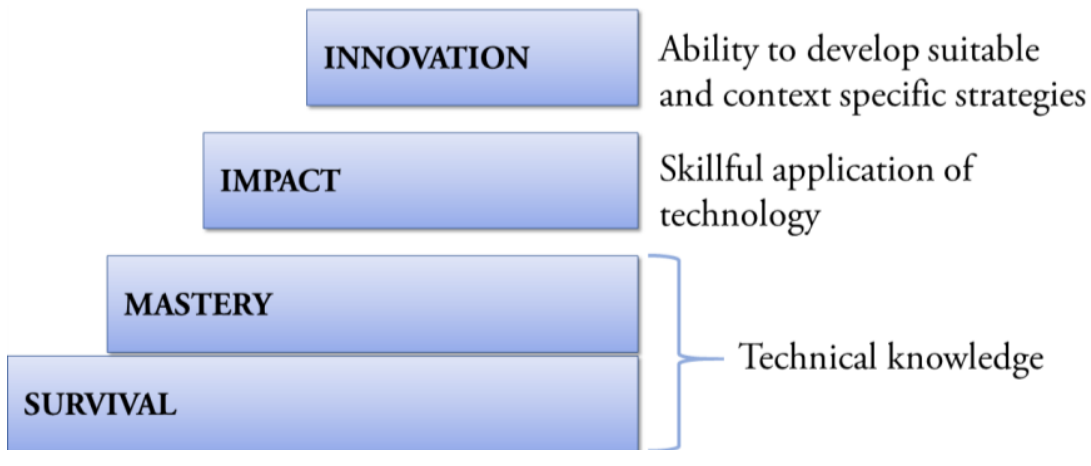

Figure 2: Competence ladder

At the first level ("technical knowledge"), which contains two of the steps in the competence ladder, the teacher getting acquainted with a variety of digital tools used in various learning environments. When the teacher feels comfortable with quickly getting to know how different digital tools work (that is mastering the technology) he or she can start to think about how to best use digital tools in a teaching context. Only after having achieved the second level ("skillful application of technology") can the technology be used in a result-oriented way and successfully integrated into the teaching; there is thus a skillful use of technology to promote learning processes. The third level ("ability to develop suitable and context specific strategies") is characterized by development of innovative and context-specific strategies to support learning processes. Important for this level is to develop and disseminate newly acquired knowledge.

The survey questions in study 1 were operationalized in relation to the competence ladder, as is shown in Table 1 below. Examples of formulations in the first two dimensions (survival/mastery) are: I feel confident in using digital tools in my teaching. / I can solve any technical problems that may arise around the digital tools I use. / I keep myself informed of new digital tools that are relevant to my field of expertise. / I often try out new digital tools. Examples of questions on the third dimension (impact) are: I feel confident in how I can choose digital tools that support and improve my teaching. / I feel confident in critically evaluating digital tools in relation to teaching. / I feel confident in how I can support and motivate my students in their learning when it comes to searching for information online. Examples of 
questions on the fourth dimension (innovation) are: I feel confident in how I can support and motivate my students to use digital tools. I I feel confident in how I can support and motivate my students in choosing relevant digital tools in relation to their education. / I am capable of critically evaluating if and how to use digital tools in my teaching.

Table 1: Categorization scheme: relation between the survey questions and the competence ladder

\begin{tabular}{lll}
\hline Dimension/level & Characteristics & Questions \\
\hline Innovation & $\begin{array}{l}\text { Experimenting; Develops; } \\
\text { Inspires }\end{array}$ & $\begin{array}{l}\text { Questions that indicate the } \\
\text { teacher's ability to inspire and } \\
\text { promote learning through the } \\
\text { use of technology. }\end{array}$ \\
Impact & $\begin{array}{l}\text { Incorporates; Understanding of } \\
\text { when and how }\end{array}$ & $\begin{array}{l}\text { Questions indicating } \\
\text { integration of digital tools in } \\
\text { teaching context. } \\
\text { Questions that indicate } \\
\text { Mastery }\end{array}$ \\
Exercises; Applying; Safety & $\begin{array}{l}\text { tools in educational contexts. } \\
\text { Questions that indicate } \\
\text { insecurity in the use of digital } \\
\text { tools in educational contexts. }\end{array}$ \\
\hline
\end{tabular}

\subsection{Study 2: focus group interview}

Six university teachers, four men and two women, participated in the focus group interview. The participants had between three and thirty years of experience in teaching in higher education. The purpose of the focus group interview was to contribute to a deeper understanding of teachers' experiences of teaching with support of digital technologies in higher education to enhance student learning. All teachers were informed about the study in writing and signed an informed consent form. They also had the option to withdraw from the interview, e.g. if they felt uncomfortable in any way. In line with ethical guidelines, the teacher's names have been anonymized and, thereby, no identifying information is provided. The focus group interview lasted for approximately 75 minutes, where the whole session was recorded, and had the nature of an informed conversation between the interviewer and the participants. The interview was based on a semi-structured interview guide that included open-ended questions such as: What does the concept of digital resources mean to you? In what ways do you think that using digital resources contributes to supporting student learning? What problems do you see when using digital resources in teaching? What kind of support is needed to enable the use of digital resources in teaching? The entire recorded material was transcribed, resulting in totally 21 pages of empirical data.

\subsubsection{Analysis of the focus group interview}

The analysis of the focus group aims to map the participants' explanations of what affects technology integration in their everyday teaching practice. This is done by relating their experiences, reasoning and associations expressed in the multi-party conversation. The analysis was performed in two steps. First, the 
content of the discussion was categorized in topics. Twelve main topics was found, each involving discourse produced by one or more of the participants (see Table 2). Then, the content of all topics was investigated again, in order to find themes that potentially reveal information about the relationship between processes on different time scales, inspired by the ecosocial approach of Lemke (2000). In order to do this, a semantic approach (Braun \& Clarke, 2006) was used in order to categorize the data. Each topic identified in the first step was reviewed for explicit or implicit references or to processes that relate to three levels, inspired by Lemke's (2000) discussion of meaning in relation to time scales:

1) The local practice in which the teacher have a high degree of control, on which events generally unfold over shorter time scales

2) The organizational level, which affect the local practice, on which events generally unfold over medium time scales

3) The societal ecology, which affect both the local practice and the organizational level, on which events generally unfold over longer time scales

\section{Results}

The results from study 1 and the survey is presented by using descriptive statistics. A main result is that the teachers estimates themselves as competent in learning about new digital technologies but do not apply their knowledge in their pedagogical practice. Although teachers generally feel secure in the use of digital technology and that they believe that they can quickly learn to use new technology, they do not test new technology to the same extent in their teaching (see Figure 3). In addition, a further result is that although teachers feel secure in the use of digital technology on an individual level, exchange at the collegiate level and in conversations with students is less frequent (see Figures 4 and 5). Another result from the survey has to do with the teachers reporting low use of features of learning management systems intended to support social and collaborative forms of learning. There is still a proportion of teachers who are not aware of the functionalities offered by the learning management system, despite the fact that it has been in use for over eight years.

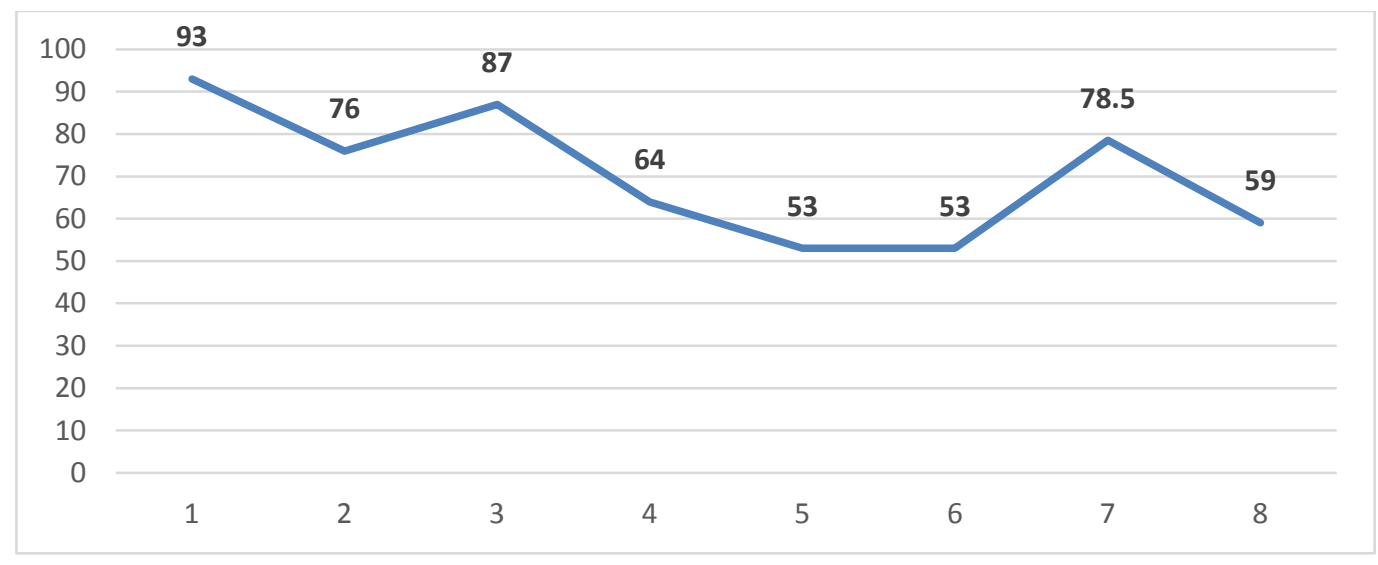

Figure 3: Percentages of respondents who totally and partially agree with statement 18 in survey question 7 
1: I feel confident in using digital tools in my teaching 2: I can solve any technical problems that may arise around the digital tools I use 3: I can quickly learn new technology 4: I stay informed of new digital tools that are relevant to my field of study 5: I often test new digital tools 6: I know quite a lot about new digital tools 7: I have the necessary basic knowledge to be able to quickly adopt the use of new digital tools 8: I have knowledge of how to choose / use digital tools that are designed to support student learning

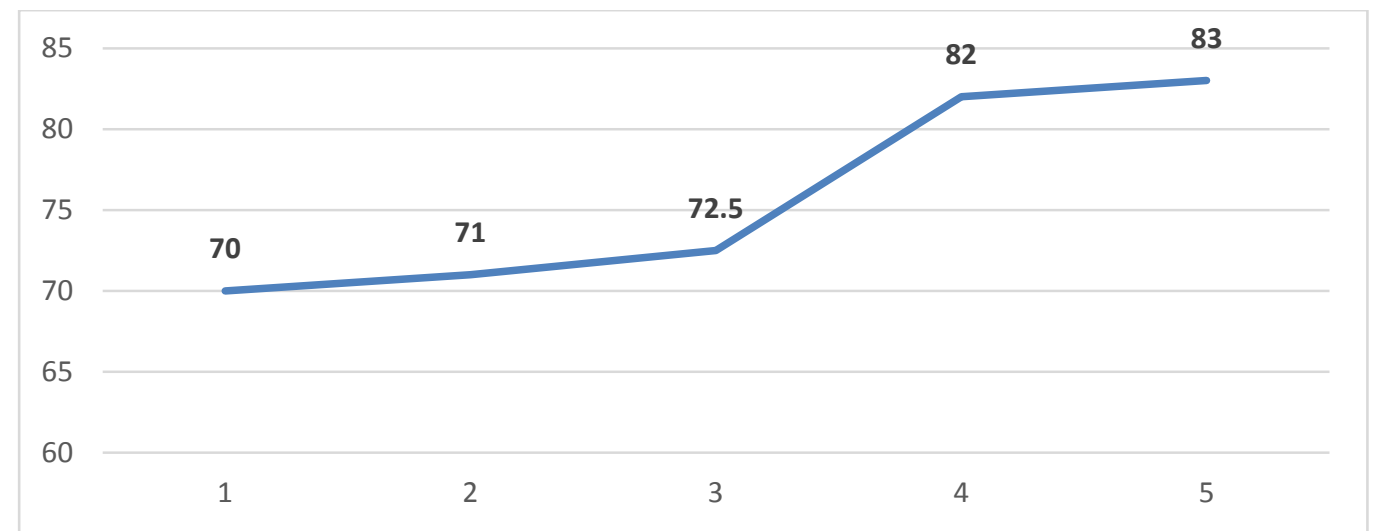

Figure 4: Percentages of respondents who totally and partially agree with statement 15 in survey question 8

1: I feel confident in finding and choosing digital tools that are suitable for teaching 2: I feel confident in how I can choose digital tools that support and improve my teaching 3: I feel confident in critically evaluating digital tools in relation to teaching 4: I feel confident in how I can support and motivate my students in their learning when it comes to searching for information on the Internet 5: I feel confident in how I can support and motivate my students in their learning when it comes to critically evaluating information on the Internet 


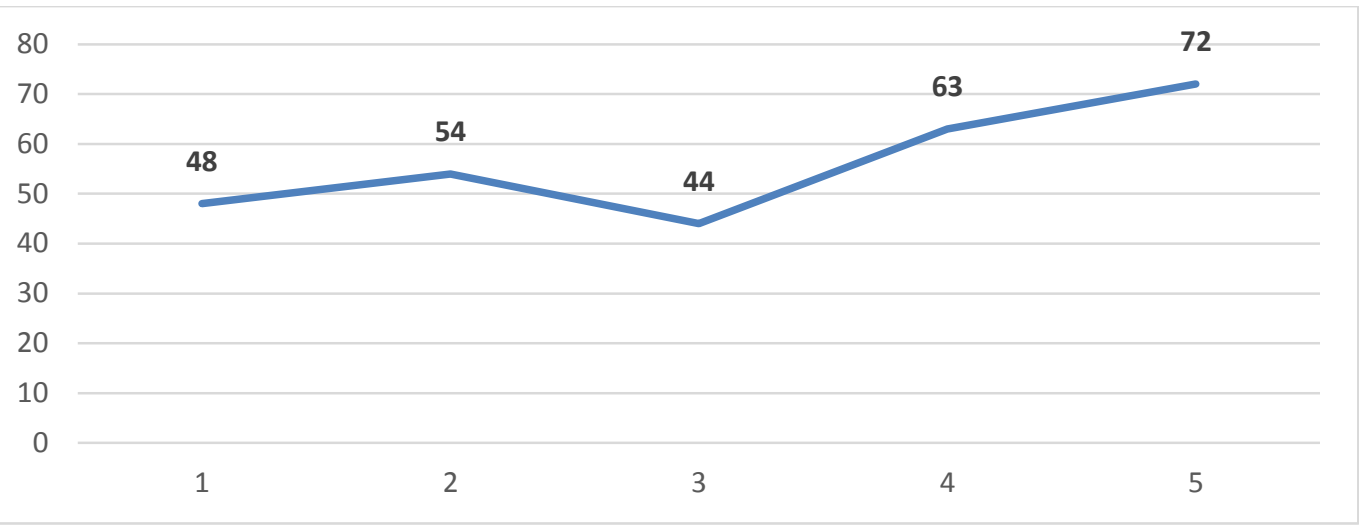

Figure 5: Percentages of respondents who totally and partially agree with statement 15 in survey question 9

1: I can help my colleagues to plan their teaching based on different teaching strategies/models with regard to subject knowledge, technology and pedagogy 2: I often talk and exchange ideas about digital tools and its use in educational settings with my colleagues 3: I often talk and exchange ideas about digital tools and its use in educational settings with my students 4: I feel confident that I can choose digital tools that support and enhance student learning 5: I am capable of critically evaluating if and how to use digital tools in my teaching

In study 2 (the focus group interview), in contrast, a lot of different questions and issues relating to the use of technologies in teaching are raised, many of which are connected to processes on level 2 and 3, beyond the direct influence of individual teachers (see Table 2). These include juridical, practical and organizational matters. Although the teachers in principle are positive to technological development, they also express concerns about it undermining the purpose of the teaching. There is an ambivalence regarding the pedagogical value of practices considered low level according to the TPACK framework.

Table 2: Topics addressed by the participants during the focus group interview and levels related to by participants $(1=$ local, $2=$ organizational and $3=$ societal)

\begin{tabular}{lll}
\hline \hline Words in topic & \multicolumn{1}{c}{ Topic title } & Relating to levels \\
\hline 1920 & Digital vs. analogue tools & $1,2,3$ \\
1630 & Support and knowledge exchange & 1,2 \\
1459 & Technical problems & 1,2 \\
1379 & Students' literacy practices & $1,2,3$ \\
1197 & Digitalization as form or content & $1,2,3$ \\
1043 & Slideshow presentations and learning & $1,2,3$ \\
1022 & The relationship between subject matter and & 1 \\
& digital resources & \\
878 & Time and planning & 1,2 \\
498 & Juridical aspects & $1,2,3$ \\
397 & Advantages with digital tools & 1,2 \\
349 & Changed expectations on the teacher & $1,2,3$ \\
283 & Unacknowledged uses of digital tools & \\
\hline
\end{tabular}

A digital tool that was mentioned in 9 out of the 12 topics was PowerPoint presentations. This reflects the results of the survey, in which PowerPoint and slide shows are rated as the most common application in teaching. In the 
analysis of the focus group, participants' reflections and reasoning provide a more in-depth picture of their situation. Although most of the teachers seemed to agree that slideshows were a central type of use of technology in their own teaching practice, a number of caveats and questions in relation to its pedagogical value came up in the conversation. Informants thus express ambivalence in relation to the use of this technology in their teaching practice. For example, Christine questions how the current established practice of lecturing based on slideshows relates to the literacy practices of students:

"There is something rational in standing by that PowerPoint and we are used to... because that is so, and that is how we plan but it is, like Thomas says, it is incredibly serial and I mean the student of today reads... behind and in front and read like almost three dimensionally... so you could wonder: can we do something else than depart from this damn PowerPoint?"

Christine expresses concern for the match between the rationale inherent in planning slideshows and the way students read information, pointing to a potential mismatch. Related issues are raised by Ulf, who suggests that the practice of lecturing using slideshows is transferring an "implicit and risky image" of learning, making the students believe that:

"It is about documenting the information, so they for example believe 'if we get these slides, well then I do not need to notes for example, or I do not need to listen so carefully, is it online yes but if you post it I can take part of it later' or they take pictures with their smartphones or so... then you miss the whole point that learning is about the active processing of information."

The concerns raised by Christine and Ulf are related but their description of the problem is quite different. In Christine's case, the student may receive too simple and 'rational' material that will not meet their more dynamic way of reading, while Ulf's analysis points to the risk that students will interpret the slideshow format as a way of collecting information rather than processing it. The teachers thus raise questions regarding the relationship between the student's literacy practices, how they actually engage with the material presented and what they learn from it, and the current established practice of lecturing using slide shows. Even if Ulf's and Christine's analyses of the situation diverge, they show that the literacy practices of students of today is an unknown factor and that it is difficult to know whether the established teaching practice using slideshows is efficient or not.

Such ambivalent considerations has consequences for the possibility to assess the relationship between means and ends in teaching, i.e. to make the rational decisions in planning teaching that are covered by the TPACK framework. If learning and teaching can be understood as a network effect with connections to processes on different time scales, like the analysis presented in Table 2 suggests, 
control over the process is not in any simple way possible to locate to the local circumstances of the teacher.

In the material, various explanations to why not more tools are utilized in the teaching practice can also be found. Besides the more well-known organizational aspects and working conditions for teachers in higher education, including lack of time and support for planning and need for concrete examples, several other issues that can be connected to processes on the societal level are addressed. For example, Thomas means that the "ocean of resources that you simply have a hard time navigating" is a "very much" limiting factor. John mentions the complex juridical situation as a "huge problem", and says that he avoids or is very careful in using learning management systems and cloud storage. He says that it "never in my mind would occur to me to use Facebook". At the same time, several of the teachers agree that the organizational norms prescribe use of digital tools. This is another example of how norms within the organization, beyond the direct control of the local teacher, are prescribing use of digital tools, while societal processes taking place on yet longer time scales are leading to developments that constraining the possibilities for meaningful planning of teaching using the TPACK framework.

\section{Discussion}

We begin the discussion with considerations of what experiences teachers in higher education have of teaching with digital technologies to support student learning, including what factors facilitate or limit these. This is followed by a discussion of the relationship between theoretical assumptions about practice in the TPACK framework and the teaching experience of university teachers. Finally, we conclude and discuss the implications of the present study for the field of higher education.

The results from study 1 provide a clear view of university teachers experiences of teaching with digital technologies to support student learning; a majority of the teachers are using quite a variety of digital tools in their teaching and feel safe in doing so. However, the results also indicate that the use in itself is limited and that there is a reluctance towards testing new technology. The discrepancy between the statements in survey question 7 (see Figure 3) can have different explanations: lack of time and a non permissive culture can be reasons why the teachers do not dare and/or have the time to test new technology or interact with colleagues, as the use of new technology in teaching means that you as a teacher need to familiarize with, problematize and reflect on how it best can serve as a means of developing teaching and student learning. Moreover, as is shown in Figures 4 and 5, teachers do not share their experiences with their colleagues to any wider extent.

This leads over to the discussion of the second research question: what elements/factors facilitate or limit teachers' use of digital technology in teaching within higher education? Drawing on Lemke (2000), three levels of ecosocial processes were introduced in the analysis of the focus group discussion. The three levels refer to 1) the local practice in which the teacher has a high degree of 
control, 2) the organizational level, which enables and constrain the local practice, and 3) the wider, societal ecology, which affect both the local practice and the organizational level.

The analysis of the focus group shows that in half of the twelve topics discussed, implicit or explicit references to processes or phenomena on all three levels were made. In four of the topics, references were made to levels one and two, while just two topics touched upon phenomena relating to the local practice only. We argue that this is a clear indication that higher education teachers' work with technology integration in teaching is closely intertwined with, and dependent on, both organizational and societal processes.

The digital technologies currently dominating universities are often developed with multiple purposes, often intertwined with organizational processes that aims to rationalize planning, administration and economy (Erlandsson, 2016). Purposes that make sense from the organizational perspective rather than individual teacher's pedagogical concerns are inherent in the design of many digital systems. Moreover, collective developments in society, taking place on an even greater time scale, are pointed out by the teachers as constraints on their ability to plan and evaluate their pedagogic use of digital tools. This is visible in the discussion of juridical issues and the impossibility of reviewing the flood of available digital tools and resources, but also in attempts to make sense of the changing student population and their literacy practices. Lemke (2000) points out that the bodies of students can be seen as a boundary objects in a network, connecting local practice with distant places and activities.

The comparison between the findings from the two studies provides the point of departure for the discussion related to the third research question: what is the relationship between theoretical assumptions about practice in the TPACK framework and the teaching experience of university teachers? The TPACK model is based on three areas of competence: subject/content, pedagogy and technology. The areas overlap and create new areas that in turn require new skills from the teacher. The core of the TPACK model is the "optimal" level of competence that shows how these three components (technology, pedagogy and content) interact to provide support for good teaching. The model is also intended to be set in relation to the current context. When teachers are confident in the use of technology, they can determine when technology facilitates or becomes an obstacle in the learning process. According to this line of reasoning, the teacher should always relate to technology as a tool that is integrated and used if and when it adds value in the teaching context (Herring, Koehler, \& Mishra, 2016).

This presupposes a sense of control over the pedagogical goals and the teaching context and that what is of value can be distinguished. A core finding in the focus group discussion is, however, that technologies are embedded in rationales that are often beyond the horizon of the individual teacher. This contrasts with the theoretical underpinnings of frameworks for the development of digital competence in education, like TPACK, which are specifically 
addressing the ability of teachers to rationally select and use technologies for their pedagogical purposes (Willermark, 2018). There is thus a gap in the understanding of the properties of technologies between the model and the reality of university teachers. We argue that one-sided theoretical assumptions about technology integration is a possible explanation of the situation where the practice and rhetoric of technology use in higher education diverge. A further question, in relation to study one analyzed here, is if surveys designed to measure individual knowledge actually may be counterproductive, as they potentially draw the organization's attention even more to the individual teachers, rather than the complex network of ecosocial relations they are embedded in.

\section{Conclusion}

Several authors have pointed out the need of involving teachers in teams (Koh, Chai \& Tay, 2014) and design processes (Pareto \& Willermark, 2019) when the TPACK framework is utilized, suggestions which are in alignment with the teachers' reasoning in this study. When it comes to teachers in higher education, the situation is potentially more complex than in primary and secondary schools as the data points to changes in student literacy, putting the established academic teaching practices and associated intellectual values in question. This coincides with the introduction of a number of different administrative tools, which are often integrated into learning management systems, which in turn often are mandatory to use in teaching.

In this way, organizational agendas emphasizing increased transparency, control and efficiency are introduced and built into digital tools, in parallel with a process in which professional values and institutional ways of relating to students are under re-negotiation, as the student population is changing. This means that the uses of technology raise questions that reach far beyond the scope of teachers and their (potential) teams. The responses to these questions are part of the processes of negotiations taking place on longer time scales, beyond the local pedagogical considerations covered by theoretical frameworks emphasizing individual competence development as a way to technology integration in higher education teaching. This is, arguably, the background against which university teachers' ambivalence about the digital transformation of higher education needs to be understood.

\section{References}

Akkaya, R. (2016). Research on the Development of Middle School Mathematics Preservice Teachers' Perceptions Regarding the Use of Technology in Teaching Mathematics. Eurasia Journal of Mathematics Science and Technology Education, 12(4), 861-879.

Bilici, S. C., Guzey, S. S., \& Yamak, H. (2016). Assessing pre-service science teachers' technological pedagogical content knowledge (TPACK) through observations and lesson plans. Research in Science \& Technological Education, 34(2), 237-251.

Braun, V., \& Clarke, V. (2006). Using thematic analysis in psychology. Qualitative Research in Psychology, 3(2), 77-101. 
Castañeda, L., \& Selwyn, N. (2018). More than tools? Making sense of the ongoing digitization of higher education. International Journal of Educational Technology in Higher Education, 15(22). doi:10.1186/s41239-018-0109-y

Erlandsson, P. (2016). A Tale from the pit - educational work at the university. Reflective Practice, 17(3), 245-256.

Herring, M. C., Koehler, M. J., \& Mishra, P. (2016). Handbook of Technological Pedagogical Content Knowledge (TPACK) for Educators. Second Edition. New York: Routledge.

Herring, M. C., Mecham, S., \& Mourlam, D. (2016). TPACK development in higher education. In M.C. Herring, M. J. Koehler \& P. Mishra (Eds.) Handbook of Technological Pedagogical Content Knowledge (TPACK) for Educators. Second Edition (pp. 207-223). New York: Routledge.

Kirkwood, A., \& Price, L. (2014). Technology-enhanced learning and teaching in Higher Education: What is 'enhanced' and how do we know? A critical literature review. Learning, Media and Technology, 39(1), 6-36.

Koh, J. H., Chai, C. S., \& Tay, L. Y. (2014). TPACK-in-Action: Unpacking the contextual influences of teachers' constructions of technological pedagogical content knowledge (TPACK). Computers \& Education, 20-29.

Lemke, J. (2000). Across the Scales of Time: Artifacts, Activities, and Meanings in Ecosocial Systems. Mind, Culture, and Activity, 7(4), 273-290.

Mandinach, E. B., \& Cline, H. F. (1992). The impact of technological curriculum innovation on teaching and learning activities. Paper presented at the Annual Conference of the American Educational Research Association, San Francisco, California. (ERIC Document Reproduction Service No. ED 345 717).

Mandinach, E. B., \& Cline, H. F. (1994). Classroom Dynamics. Implementing a TechnologyBased Learning Environment. New York: Routledge.

Mishra, P. (2011). Using the TPACK Image. Reprinted and retrieved from http:/ / www.tpack.org by permission of the publisher, copyright 2012 by tpack.org.

Mishra, P., \& Koehler, M. J. (2006). Technological Pedagogical Content Knowledge: A Framework for Teacher Knowledge. Teachers College Record, 108, 1017-1054.

Pareto, L., \& Willermark, S. (2019). TPACK in situ: A Design-based Approach Supporting Professional Development in Practice. Journal of Educational Computing Research, 57(5), 1186-1226.

Price, L., \& Kirkwood, A. (2014). Using technology for teaching and learning in Higher Education. A critical review of the role of evidence in informing practice. Higher Education Research and Development, 33(3), 549-564.

Redecker, C. (2017). European Framework for the Digital Competence of Educators: DigCompEdu. EUR 28775 EN. Publications Office of the European Union, Luxembourg.

Roumbanis V. A., Forslund F. K., \& Sofkova H. S. (2019). Teacher educators' perceptions of their profession in relation to the digitalization of society. Journal of Praxis in Higher Education, 1(1), 87-110.

Sancar-Tokmak, H., \& Yanpar-Yelken, T. (2015). Effects of creating digital stories on foreign language education pre-service teachers' TPACK self-confidence. Educational Studies, 41(4), 444-461.

Selwyn, N. (2014). Digital Technology and the Contemporary University: Degrees of Digitization. London: Routledge.

Shulman, L. S. (1986). Those who understand: Knowledge growth in teaching. Educational Researcher, 15(2), 4-31. 
Singh, G., \& Hardaker, G. (2014). Barriers and enablers to adoption and diffusion of eLearning: a systematic review of the literature - a need for an integrative approach. Education and Training, 56(2-3), 105-121.

Taylor, T. (2014). Tackling Assumptions and Expectations; Implementing Technology in Higher Education. International Journal of Learning, Teaching and Educational Research, 1(1), 1-13.

Willermark, S. (2018). Technological Pedagogical and Content Knowledge: A Review of Empirical Studies Published From 2011 to 2016. Journal of Educational Computing Research, 56(3), 315-343.

\section{Biographies}

\section{Jeanette Sjöberg}

Jeanette Sjöberg is working as a senior lecturer in pedagogy and as head of the Centre for educational development at Halmstad University. Currently, she is involved in teaching pedagogical courses for university teachers as well as in strategic development work on an organizational level. Her research interest is focusing on learning, teaching and development in higher education in relation to digital/new technology and how learning strategies are developed in relation to new technologies.

\section{Patrik Lilja}

Patrik Lilja is an educational researcher and developer with a long-standing interest in the relationship between technology, teaching and learning in institutional settings. He is currently working as a senior lecturer and is leading educational development projects at the Centre for educational development at Halmstad University. His research deals with children's and students' use of digital technologies and their understanding of technological concepts. 